\title{
Cutting-edge therapies in the treatment of surgical wounds
}

\author{
José M. Zepeda*, Javier Contreras, Felix Osuna, Melany Jimenez, Alejandro Murrieta
}

School of Medicine, Autonomous University of Guadalajara, Guadalajara, Jalisco, Mexico

Received: 08 November 2021

Revised: 02 December 2021

Accepted: 03 December 2021

*Correspondence:

Dr. Jose M Zepeda,

E-mail: josem.zepeda@edu.uag.mx

Copyright: ( ) the author(s), publisher and licensee Medip Academy. This is an open-access article distributed under the terms of the Creative Commons Attribution Non-Commercial License, which permits unrestricted non-commercial use, distribution, and reproduction in any medium, provided the original work is properly cited.

\begin{abstract}
Wounds are inherent to being alive and also a reminder of our fragility in the face of the hostilities of this planet. Annually, it is estimated that 4511 operations are performed per 100,000 population, or 1 surgical procedure every year for every 22 people. There is an art to treating wounds. The support by the doctor for wound healing favors the early recovery of this, in addition to minimizing the risk of infection and gives an aesthetically pleasing appearance, the care that is used today ranging from the cleaning of the wound, the approximation of the edges thanks to the sutures, etc. The following is a review of cutting-edge therapies in this area of medicine, such as biotechnologies, growth factors, gene therapy, and stem cells. Projections indicate an increasing decrease in morbidity and mortality associated with surgical wounds and their repair, as well as more favorable cosmetic outcomes for patients. The results showed that all the described techniques, although not perfect, are perfectible, and with the pertinent precautions can be maximized in favor of care. There is the possibility in the near future, to be a basic part of wound care, in terms of protocols of care, but also in the individualization of treatment.
\end{abstract}

Keywords: Surgical wound, Cutting-edge, Growth factors, Genter therapy, Stem cells

\section{INTRODUCTION}

Man from his origins, and on his way through this world full of constant threats, has been the victim of wounds that put his life at risk. Wounds, then, are inherent to being alive and also a reminder of our fragility in the face of the hostilities of this planet. However, the scars resulting from this constant exposure to the environment in which we develop are directly contrary and in turn, is an imprint of our strength and resilience, an objective and even poetic vision of the dynamism of life and the own amazing ability to adapt that keeps us alive, is therefore, the masterful proof that we are life. Even so, this system of wound repair is far from perfect, since it is subject to an immense variety of factors, both intrinsic and extrinsic, which directly or indirectly affect this fine process and can cause defects in it. It took a long time before we could just begin to understand the processes involved in wound healing. Measures such as keeping wounds in a moist environment were observed to heal better than those exposed to air, as moisture prevents dehydration and desiccation of the wound with an interface between the wound and the environment. This led to insist on the importance of maintaining a moist environment in order to ensure proper healing, even consistently proved that the rate of epithelialization increases $50 \%$ in a moist environment compared to wounds under a dry environment. ${ }^{1,2}$

Annually, it is estimated that 4511 operations are performed per 100,000 population, or 1 surgical procedure per year for every 22 people. Worldwide, surgical wounds are most often treated in acute care settings and are associated with a wide range of complications such as bleeding and dehiscence. ${ }^{3}$

The fact of treating wounds is an art, because they must take into account many concepts inherent to the human 
being, in addition to the biological and molecular field, use them as tools and finally, avoid infections, recover tissue functionality and its barrier effects, and ultimately, achieve aesthetically satisfactory results. Despite the exponential advances we have had in wound treatment, complications or the final result of these can leave much to be desired, even under strict protocols of asepsis and antisepsis, as it is in the operating room. It is for the reasons stated in the previous lines that this review paper aims to present the therapies that today, are avant-garde and with promising results in order to reduce the rate of complications and increase aesthetic satisfaction in a controlled environment such as surgical wounds. In the theoretical framework, a general approach to tissue repair will be addressed in order to understand the mechanism of action of the different therapies to be presented immediately afterwards.

\section{METHODS}

For this work, a search was carried out in publications in scientific journals about, avant-garde therapies in the treatment of surgical wounds, as well as a review of the literature.

\section{Theoretical framework}

Overview of tissue repair in first intention healing. In a clean, uninfected surgical incision with edge approximation, disruption is exclusively of the basement membrane, with reduced cell death; wounds activate clotting pathways by exposure of collagen; the clot stops bleeding and supports migrating cells; once dehydrated, a scab forms. ${ }^{1,4,11,19,20}$ Over the next $24 \mathrm{~h}$, neutrophils approach the edge of the incision to remove debris. By 24-48 h, epithelial cells have successfully migrated along both edges to proliferate along the dermis, depositing basement membrane components as they go. ${ }^{4}$ On day 3, the predominant cells are macrophages and granulation tissue occupies the incision space, with collagen fibers easily identifiable at the edges of the incision. ${ }^{4-6}$ By day 5 , the neovascularization achieved is at its peak with ongoing migration of fibroblasts, which produce extracellular matrix proteins. ${ }^{6,7}$ The epidermis regains its usual thickness as superficial cell differentiation gives way to a mature epidermal architecture with superficial keratinization. ${ }^{6,8}$ In the second week, there is a constant accumulation of collagen and fibroblastic proliferation, as well as a decrease in leukocyte infiltrate, edema and vascularization. ${ }^{9}$ By the fourth week, the scar is well formed, with few inflammatory cells. Although the epidermis is essentially normal, the affected dermis at the incision line is definitely lost. ${ }^{4}$ When these processes are properly executed, the scar is minimally visible. 15Even those meticulously cared for wounds do not preserve the same strength of normal skin. ${ }^{4}$

Overview of tissue repair in second intention healing. Second intention healing has a place in situations where tissue loss is more extensive. ${ }^{5,6}$ The repair is a combination of regeneration and healing. The formation of an extensive scar is explained by the large deposition of extracellular matrix directly proportional to the extent of the wound and the inflammatory reaction, followed by contraction of the wound by myofibroblasts; extensive skin defects can contract in a time of up to 6 weeks., ${ }^{4,5}$

The support by the doctor for the wound healing favors the prompt recovery of the same, in addition to minimizing the risk of infection and gives an aesthetically satisfactory appearance, the care that is used today ranging from the cleaning of the wound, the approximation of the edges thanks to the sutures, etc., however, the following is a review of cutting-edge therapies in this area of medicine.

\section{Biotechnological}

As for conventional treatment different grafts are used; the autograft is classified as partial thickness in which the epidermis is implanted with a thin part of the dermis, or full thickness which consists of a radical implant of the dermis, in this therapeutic modality there is a low risk (almost null) of rejection because it is taken from the same patient, almost always using the inner thighs, buttocks and in cases where the epidermis is very thin as senile patients can be taken from the lower back. Currently the full thickness graft is being studied for repair of incisional hernias, it has been found that the use of autologous material is cheaper than synthetic mesh, also preferable in terms of histoimmunological perspective, in a randomized multicenter study of 50 patients the results and complications were similar in both treatment modalities, although those operated with graft reported less pain compared to the mesh group $(13 \%) .{ }^{10}$

Allografts, which generally use cadaveric skin, are the most commonly used for the healing of extensive burns because, in addition to providing an effective barrier, they promote angiogenesis, production of growth factors and cytokines essential for healing. In a study conducted in the United States, dehydrated human chorion amnion was used for the treatment of chronic ulcers in the lower extremities of 126 diabetic patients, and it was found that subjects who underwent this type of allograft were more than twice as likely to heal in 12 weeks than patients in whom only conventional treatment was used. ${ }^{11}$

Among the most frequent adverse effects of graft implantation are infections (cellulitis, osteomyelitis), three events were classified with a possible relationship with the product studied, predominantly pseudomonas aeruginosa as the causal agent.

Xenografts use skin from a different species, usually porcine; they are used as temporary grafts for wounds, this provides aid to dermal regeneration by the fusion of exogenous collagen. ${ }^{12}$ Porcine skin shares many similarities with human skin, a challenge for the use of 
porcine xenografts is the high susceptibility to rejection by preformed antibodies against $\alpha$ - 1,3-galactose (GAL), present in porcine cells. The study genetically modified the graft by creating GALT-KO, and demonstrated that this in combination with intramuscular cyclosporin $\mathrm{A}$ at doses of $13-15 \mathrm{mg} / \mathrm{kg} /$ day can provide temporary wound coverage for up to 11 days. ${ }^{12}$

Other skin substitutes such as Permacol, Matriderm and Oasis belong to the category of xenografts. Permacol is made from pig skin, while MATRIDERM $®$ is made from a matrix of bovine type I collagen with elastin. ${ }^{13}$

Acellular skin substitutes are composed of a nylon or collagen mesh (dermis) and a silicone membrane that supplies the epidermal function, some examples are Biobrane ${ }^{\circledR}$, Integra ${ }^{\circledR}$ and Alloderm ${ }^{\circledR} .{ }^{13}$ Allogeneic cell substitutes come from live fibroblasts of the neonatal foreskin, currently available on the market are Transcyte ®, Dermagraft $\AA$, Apligraf $\AA$, and Graftskin ${ }^{\circledR}$, are used as treatment of venous and diabetic ulcers, burns, vestibuloplasty, even epidermolysis bullosa, etc. ${ }^{13}$

As for autologous cell substitutes, they are divided into: cultured epidermal autograft (CEA) and cultured skin substitutes (CSS).

CEA consists of cultured keratinocytes derived from the patient's biopsy, common adverse effects are hyperkeratosis and contractures. CSS contain dermal and epidermal elements, stimulate fibroblast mobilization, control osmoregulation and extracellular matrix hydration.
In summary, the preparation of the fissure-engineered skin substitute consists of a biopsy of the patient's skin, cell isolation (keratinocytes and fibroblasts), cell culture in monolayers, and finally the conditioning of the graft to be implanted.

Growth factors. Growth factors target cell proliferation in those cells that are at steady state, as well as after injury, when irreversibly damaged cells must be replaced. ${ }^{4,14}$ Several growth factors are involved in fetal healing without scarring. ${ }^{15}$ Those wounds that do not heal, or heal inadequately, are thought to be the result of growth factor deficiency or the presence of antagonistic factors in the wound environment. Today, thanks to the advent of genetic engineering, as well as advances in biotechnology, many growth factors are known to exert beneficial effects with potential for surgical use, including PDGF, VEGF, FGF, epidermal growth factor (EGF), keratinocyte growth factor (KGF), transforming growth factor beta (TGF- $\beta$ ), granulocyte-macrophage colony-stimulating factor (GM-CSF), basic fibroblast growth factor (bFGF), and others. ${ }^{4,14}$ Currently, several drugs have already been approved, including recombinant growth factors, are available as preparations for external use in the form of lotions, ointments, creams, and gels. ${ }^{4,14}$ For diabetic foot ulceration, PDGF, VEGF and EGF are already used topically with excellent results, as in a randomized controlled trial, PDGF-BB (Regranex ${ }^{\circledR}$ ) was compared to placebo in 118 patients with non-healing diabetic ulcers. Patients were treated for 20 weeks or until complete wound closure.

Table 1: Growth factors and their functions.

\begin{tabular}{|ll|l|}
\hline $\begin{array}{l}\text { Growth factor } \\
\text { Epidermal growth factor } \\
\text { (EGF) }\end{array}$ & $\begin{array}{l}\text { Sources } \\
\text { Activated macrophages, salivary glands, } \\
\text { keratinocytes and many other cells }\end{array}$ & $\begin{array}{l}\text { Mitogenic for keratinocytes and } \\
\text { fibroblasts; stimulates keratinocyte } \\
\text { migration; stimulates granulation tissue } \\
\text { formation }\end{array}$ \\
\hline $\begin{array}{l}\text { Transforming Growth Factor- } \\
\boldsymbol{\alpha} \text { (TGF- } \boldsymbol{\alpha} \text { ) }\end{array}$ & $\begin{array}{l}\text { Activated macrophages, keratinocytes, } \\
\text { many other types of cells }\end{array}$ & $\begin{array}{l}\text { Stimulates proliferation of hepatocytes } \\
\text { and many other epithelial cells. }\end{array}$ \\
\hline $\begin{array}{l}\text { Hepatocyte growth factor } \\
\text { (HGF) (dispersion factor) }\end{array}$ & $\begin{array}{l}\text { Fibroblasts, stromal cells in the liver, } \\
\text { endothelial cells }\end{array}$ & $\begin{array}{l}\text { Enhances proliferation of hepatocytes } \\
\text { and other epithelial cells; increases cell } \\
\text { motility }\end{array}$ \\
\hline $\begin{array}{l}\text { Vascular endothelial growth } \\
\text { factor (VEGF) }\end{array}$ & Mesenchymal cells & $\begin{array}{l}\text { Stimulates endothelial cell proliferation; } \\
\text { increases vascular permeability }\end{array}$ \\
\hline $\begin{array}{l}\text { Platelet-Derived Growth } \\
\text { Factor (PDGF) }\end{array}$ & $\begin{array}{l}\text { Platelets, macrophages, endothelial } \\
\text { cells, smooth muscle cells, } \\
\text { keratinocytes }\end{array}$ & $\begin{array}{l}\text { Chemotactic for neutrophils, } \\
\text { macrophages, fibroblasts and smooth } \\
\text { muscle cells; activates and stimulates } \\
\text { proliferation of fibroblasts, endothelial } \\
\text { and other cells; stimulates synthesis of }\end{array}$ \\
\hline $\begin{array}{l}\text { Fibroblast growth factors } \\
\text { (FGF), including acid (FGF-1) } \\
\text { and basic (FGF-2) }\end{array}$ & $\begin{array}{l}\text { Macrophages, mast cells, endothelial } \\
\text { cells, many other types of cells }\end{array}$ & $\begin{array}{l}\text { Chemotactic and mitogenic for } \\
\text { fibroblasts; stimulates angiogenesis and } \\
\text { ECM protein synthesis }\end{array}$ \\
\hline
\end{tabular}


Of the PDGF- treated patients, $48 \%$ healed compared to $25 \%$ of the placebo-treated patients. Three additional clinical trials reached similar conclusions. ${ }^{14}$ EGF also has applications in the field of burns and nonhealing ulcers, being applied both topically and intralesionally. ${ }^{14}$ On the other hand, bFGF and GM-CSF are used in the treatment of pressure and venous ulcers. ${ }^{14}$ Regarding TGF, its isoform TGF- $\beta 1$ promotes wound healing, it can also promote fibrosis when it is not controlled. In contrast, TGF- $\beta 3$ may have an antifibrotic role in wound healing. ${ }^{14,16}$ In the surgical management of burns, one of the endpoints is to decrease catabolism and increase anabolism. Insulin, insulin-like growth factor 1 , and growth hormone have all been shown to have a benefit but are rarely used. ${ }^{16} \mathrm{~A}$ Level 1 study compared the efficacy and safety of SKN2017B, which is a proprietary topical cream based on synthetic, selective human growth factors and hyaluronic acid, against a silicone-based silicone cream specifically formulated for the treatment of post-surgical scars; At 12 weeks, the investigators rated $74 \%$ of scars treated with SKN2017B as showing overall improvement versus $54 \%$ of scars treated with silicone, a relative improvement of $73 \%$ with SKN2017B $(\mathrm{p}<0.0001)$.

Patients rated moderate to significant improvement in $85 \%$ of SKN2017B-treated scars versus $51 \%$ of siliconetreated scars, 67\% relative improvement with SKN2017B $(\mathrm{p}<0.001)$. The independent reviewers rated $87 \%$ of SKN2017B-treated scars as better overall versus $1 \%$ of silicone-treated scars $(\mathrm{p}<0.0001){ }^{17}$

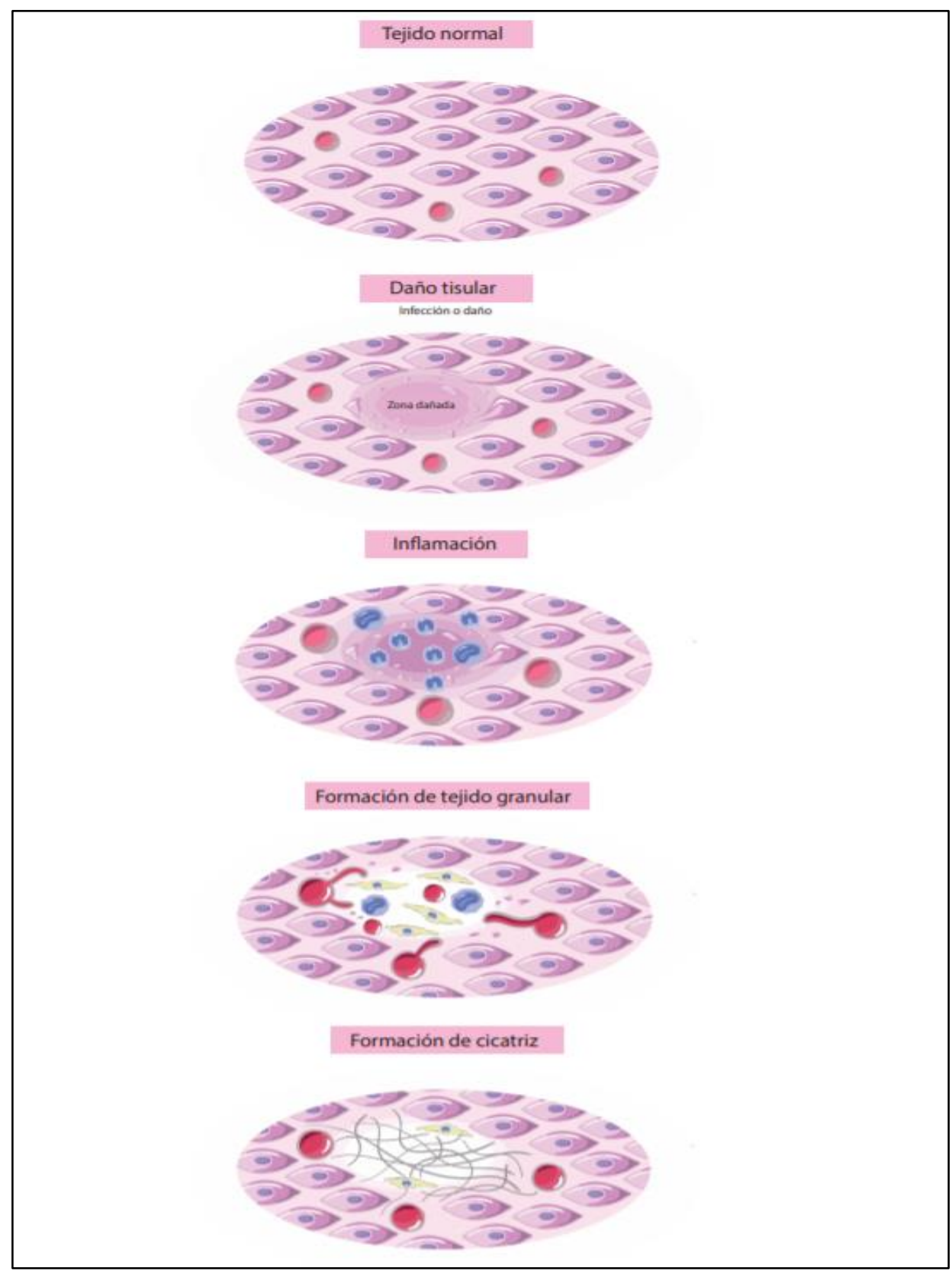

Figure 1: General mechanism of tissue repair. 
Despite the promising results that have been shown with these therapies based on growth factors and the milestone that has been reached since 2018 with the increase in the manufacture of the same, one of the causes that hold back their more widespread use is the potential oncogenic effect that is inherent to uncontrolled growth, and is that, the learning curve for the application of these in combination with surgical techniques is large and a field of study that to date, is in development. Some studies point to the role of honey as a promoter of the release of growth factors. ${ }^{17}$

\section{Gene therapy}

Gene therapy is defined as the insertion of a gene into the recipient cells, initially it was only considered as a treatment option for patients with a congenital defect where their metabolic function is compromised or a late stage malignant process. ${ }^{18}$ Recently, the skin has become an important target for research in gene therapy for improved healing and for all those whose tissue repair processes are compromised. This process is made possible by the ease of harvesting and culturing fibroblasts and keratinocytes, which allows for in vitro gene transfer testing and the use of skin cells as vehicles for gene transfer. The skin is also easily accessible and the effects of therapy can be monitored repeatedly. Two basic strategies for the introduction and expression of foreign DNA into host cells are: Gene therapy, which is based on the permanent insertion of DNA, gene medicine, which is used for the transient transformation and short-term expression of a gene product. ${ }^{21}$

Genes can be delivered through in vivo or ex vivo approaches. In both approaches, the selection of an appropriate vector for gene introduction is critical for success. One of the goals of gene therapy is that it enables the cell to synthesize a protein that has a novel therapeutic effect, in this case accelerating wound repair. ${ }^{21}$ However, for this therapy to be considered it is important to inform the patient that this will be intervened at the molecular level where it is expressed in detail all the effects that this can produce. In order to reach the clinical application of gene therapy, there must be ample and solid scientific evidence that demonstrates that the intervention at the molecular level could result in the improvement of the patient's health, or in the solution of the health problem that is being treated. In addition, the cost to be absorbed by the patient may be high compared to other types of cutting-edge therapies.

Stem cells. The skin is the largest organ of the body and has a variety of functions. The skin compartments, epidermis and hair follicles harbor stem cells that are indispensable for skin homeostasis and regeneration. These stem cells contribute to wound repair, resulting in the restoration of tissue integrity and function of damaged tissue. Failed wound healing processes often lead to nonhealing wounds. Chronic wounds are caused by stem cell depletion and a variety of other cellular and molecular mechanisms, many of which are still poorly understood. Current therapies for chronic wounds are limited and generally do not meet patients' expectations, so the search to develop better therapeutic strategies is ongoing, which launches stem cell therapies as a strong candidate, as when applied to the body their effects help to activate the regenerative potential of resident stem cells or even through tissue engineering. The use of stem cell therapies to treat these wounds results in improved cell signaling, release of growth factors and cytokines, neovessel formation and immunomodulatory properties.

Mesenchymal stem cells secrete growth factors and interleukins -ANGPT2, BMP2, BMP3, BMP4, BMP7, CCL2, CCL3, CSF2, CSF3, CXCL12, EGF, FGF2, FGF4, FLT3, FLT3LG, GDF5, HGF, IFNG IGF1, IGF2, IL17A, IL1A, IL1B, IL3, IL4, IL6, KITLG, LIF, MSTN, PDGFA, PDGFB, TGFB1, TGFB2, TGFB3, TNF, VEGFA, VEGFC- which support dermal fibroblast proliferation by direct cell-to-cell contact and by paracrine activation during the proliferation phase.

Mesenchymal stem cells derived from adipose tissue have demonstrated clinical efficacy in the treatment of chronic wounds secondary to severe radiation injury, chronic fistulas and ulcerations, including venous leg ulcers. $^{24}$

Adipose tissue-derived mesenchymal stem cells accelerate wound healing and exhibit antioxidant effects under various conditions; these are mainly mediated by activation of dermal fibroblasts and keratinocytes through the paracrine mechanism. ${ }^{25}$

The secretion of anti-apoptotic and anti-inflammatory angiogenic factors from adipose tissue- derived mesenchymal stem cells increases with exposure to stimuli such as hypoxia, TNF- $\alpha$ and lipopolysaccharide, which enhance the regenerative function of adipose tissue-derived mesenchymal stem cells. ${ }^{25}$

Mesenchymal stem cells (MSCs) exhibit direct antimicrobial properties that are mediated by the secretion of the antimicrobial peptide LL-37. ${ }^{22,23,26-28}$ For all the above reasons, it makes sense that the application of mesenchymal stem cell infusion therapies is an excellent option to catalyze the body's healing tools.

\section{DISCUSSION}

The invoicing methods of the articles cited in this document were refined, in addition to validating each other, likewise with respect to what appears in the literature. The impact of this product is promising, as far as individualized treatment is concerned, the projections indicate an increasing decrease in morbidity and mortality associated with surgical wounds and their repair, likewise, the aesthetic results are more favorable for patients, having a direct psychological impact on their self-perception, improving their quality of life. Perhaps 
the most promising for the future will be the addition of gene therapy and the addition of growth factors, for adequate wound control, once the methods for carrying out and implementing these therapies have been refined. ${ }^{4,14,21-25}$

\section{CONCLUSION}

Definitely the execution of this work of literature review has been deeply enriching in the formation of the authors of the work, as it has served as a bridge between the knowledge in basic sciences, and its application to clinical practice in its most specialized and interesting branches, in turn, there is the possibility in the near future, be a basic part of wound care, in terms of protocols of care, but also in the individualization of treatment, since we firmly believe that care should be personal, seeking the greatest benefit to the patient. The results showed that all the techniques described are not perfect, but they are perfectible, and with the appropriate precautions can be maximized for the benefit of care. Finally, the researchers are encouraged to continue to reproduce the results of the tests so that they become more and more solid.

\section{Funding: No funding sources \\ Conflict of interest: None declared \\ Ethical approval: Not required}

\section{REFERENCES}

1. Castellanos-Ramirez D, Gonzalez-Villordo D, Gracia-Bravo L. Wound management. Cirujano General. 2014;32(2):112-20.

2. Winter GD. Formation of the Scab and the Rate of Epithelization of Superficial Wounds in the Skin of the Young Domestic Pig. Nature. 1962;193(4812):293-4.

3. Gillespie BM, Walker RM, Mcinnes E, Moore Z, Eskes AM, O'connor $\mathrm{T}$, et al. Preoperative and postoperative recommendations to surgical wound care interventions: A systematic meta-review of Cochrane reviews. International Journal of Nursing Studies. 2020;102:103486.

4. Geoffrey GC, Sabine W, Yann B, Michael LT. Wound repair and regeneration. Wound Repair and Regeneration. 2008;453(7193): 314-21.

5. Page-McCaw A, Ewald AJ, Werb Z. Matrix metalloproteinases and the regulation of tissue remodelling. Nature Reviews Molecular Cell Biology. 2007;8(3):221-33.

6. Thomas WA, Thirumalai R. Mechanisms of fibrosis: therapeutic translation for fibrotic disease. Nature Medicine. 2012;18(7):1028-40.

7. Wick G, Grundtman C, Mayerl C, Wimpissinger TF, Feichtinger J et al. The Immunology of Fibrosis. Annual Review of Immunology. 2013;31(1):107-35.

8. Novak ML, Koh TJ. Macrophage phenotypes during tissue repair. Journal of Leukocyte Biology. 2013;93(6):875-81.
9. Grompe M. Tissue Stem Cells: New Tools and Functional Diversity. Cell Stem Cell, 2012;10(6):685-9.

10. Agarwal P, Sharma D. Comment to: Full thickness skin graft vs. synthetic mesh in the repair of giant incisional hernia: a randomized controlled multicenter study. Clay L, Stark B, Gunnarsson U, Strigård K. Hernia. 2018;22(6):999-1000.

11. Tettelbach W, Cazzell S, Reyzelman AM, Sigal F, Caporusso JM, Agnew PS. A confirmatory study on the efficacy of dehydrated human amnion/chorion membrane dHACM allograft in the management of diabetic foot ulcers: A prospective, multicentre, randomised, controlled study of 110 patients from 14 wound clinics. International Wound Journal. 2018;16(1):19-29.

12. Barone AAL, Mastroianni M, Farkash EA, Mallard C, Albritton A, Torabi R, et al. Genetically modified porcine split-thickness skin grafts as an alternative to allograft for provisional of temporary wound coverage: preliminary characterization. Burns. 2015;41(3):565-74.

13. Vig K, Chaudhari A, Tripathi S, Dixit S, Sahu R, Pillai S, et al. Advances in Skin Regeneration Using Tissue Engineering. International Journal of Molecular Sciences. 2017;18(4):789.

14. Yamakawa S, Hayashida K. Advances in surgical applications of growth factors for wound healing. Burns \& amp. Trauma. 2019;7.

15. Zoumalan CI, Tadayon SC, Roostaeian J, Rossi AM, Gabriel A. Safety and Efficacy of a Scar Cream Consisting of Highly Selective Growth Factors Within a Silicone Cream Matrix: A DoubleBlinded, Randomized, Multicenter Study. Aesthetic Surgery Journal. 2018;39(3):319-30.

16. Greenhalgh DG. Management of Burns. New England Journal of Medicine. 2019;380(24):234959.

17. Oryan A, Alemzadeh E, Moshiri A. Biological properties and therapeutic activities of honey in wound healing: A narrative review and metaanalysis. Journal of Tissue Viability. 2016;25(2):98118.

18. Ginn SL, Amaya AK, Alexander IE, Edelstein M, Abedi MR. Gene therapy clinical trials worldwide to 2017: An update. The Journal of Gene Medicine. 2018;20(5).

19. Kremers BMM, Cate HT, Spronk HMH. Pleiotropic effects of the hemostatic system. Journal of Thrombosis and Haemostasis. 2018;16(8):1464-73.

20. Versteeg HH, Heemskerk JWM, Levi M, Reitsma PH. New Fundamentals in Hemostasis. Physiological Reviews. 2013;93(1):327-58.

21. Jiang DJ, Xu CL, Tsang SH. Revolution in Gene Medicine Therapy and Genome Surgery. Genes. 2018;9(12):575.

22. Ullah I. Human mesenchymal stem cells - current trends and future prospective. Bioscience Reports. 2015;35(2):e00191. 
23. Singh G. Cytokine regulation of stem cells. Peer J Preprints. 2016.

24. Kim WS, Park BS, Sung JH, Yang JM, Park SB, Kwak SJ, et al. Wound healing effect of adiposederived stem cells: A critical role of secretory factors on human dermal fibroblasts. Journal of Dermatological Science. 2007;48(1):15-24.

25. Kim WS, Park BS, Sung JH. The wound-healing and antioxidant effects of adipose-derived stem cells. Expert Opinion on Biological Therapy. 2009;9(7):879-87.

26. Alcayaga-Miranda F, Cuenca J, Khoury M. Antimicrobial Activity of Mesenchymal Stem Cells: Current Status and New Perspectives of
Antimicrobial Peptide-Based Therapies. Frontiers in Immunology. 2017;8.

27. Esfandiyari R, Halabian R, Behzadi E, Sedighian H, Jafari R, Fooladi AAI. Performance evaluation of antimicrobial peptide $11-37$ and hepcidin and $\beta$ defensin-2 secreted by mesenchymal stem cells. Heliyon. 2019;5(10).

28. Abbas AK, Lichtman AH, Pillai S. Cellular and molecular immunology. Johanneshov: MTM. 2019.

Cite this article as: Zepeda JM, Contreras J, Osuna F, Jimenez M, Murrieta A. Cutting-edge therapies in the treatment of surgical wounds. Int Surg J 2022;9:249-55. 